OPEN ACCESS

Edited by:

Barbara Melosky,

University of British Columbia,

Canada

Reviewed by:

Timothy F. Burns,

University of Pittsburgh Cancer

Institute, USA

Desiree Hao,

University of Calgary, Canada

${ }^{*}$ Correspondence:

Annick Wong

annick1@gmail.com

Specialty section: This article was submitted to

Thoracic Oncology, a section of the journal

Frontiers in Oncology

Received: 08 December 2016 Accepted: 24 February 2017

Published: 05 April 2017

Citation:

Wong A (2017) The Emerging

Role of Targeted Therapy and

Immunotherapy in the Management of Brain Metastases in Non-Small

Cell Lung Cancer.

Front. Oncol. 7:33.

doi: 10.3389/fonc. 2017.00033

\section{The Emerging Role of Targeted Therapy and Immunotherapy in the Management of Brain Metastases in Non-Small Cell Lung Cancer}

\author{
Annick Wong ${ }^{1,2 *}$ \\ ${ }^{1}$ Medical Oncology, McGill University Health Centre, Montreal, QC, Canada, ${ }^{2}$ Medical Oncology, Hôpital du Suroit, \\ Valleyfield, QC, Canada
}

Lung cancer is the worldwide leading cause of cancer-related mortality in men and second leading in women. Brain metastases (BM) account for $10 \%$ of non-small cell lung cancer (NSCLC) patients at initial presentation, with another $25-40 \%$ developing BM during the course of their disease. In the last decade, the field of precision oncology has led to the discovery of a multitude of heterogenous molecular abnormalities within NSCLC as well as the development of tyrosine kinase inhibitors that target them. In this review, the focus will be on targeted therapy and immunotherapy that show efficacy in BM rather than conventional treatment for multiple BM (such as surgical resection, WBRT, or stereotactic radiosurgery).

Keywords: brain metastases, non-small cell lung cancer, targeted therapies, immunotherapy, intracranial responses

\section{INTRODUCTION}

Lung cancer is the worldwide leading cause of cancer-related mortality in men and second leading in women (1). Brain metastases (BM) account for $10 \%$ of non-small cell lung cancer (NSCLC) patients at initial presentation (2), with another $25-40 \%$ developing BM during the course of their disease (3). The general metastatic NSCLC population survival is approximately 12 months, with a median progression-free survival (PFS) range from 3 to 6 months (4). BM are associated with poor prognosis, and the median survival ranges from 2.4 to 4.8 months for patients with BM who receive whole-brain radiation therapy (WBRT) (5). While the standard of care for BM remains radiotherapy, determining the optimal treatment between high-dose-focused radiations via stereotactic radiosurgery (SRS) alone versus WBRT remains controversial. A retrospective multi-institutional retrospective study showed a survival advantage in patients with fewer than four BM less than $4 \mathrm{~cm}$ in size $(n=189$ for NSCLC) who were treated with SRS compared to those treated with WBRT [adjusted hazard ratio (HR) for NSCLC, $0.58 ; 95 \%$ confidence interval (CI), 0.38-0.87; $P=0.01]$ (6).

The treatment of BM is important in maintaining a good quality of life and limiting cognitive impairment and neurological dysfunction. In the last decade, the field of precision oncology has led to the discovery of a multitude of heterogenous molecular abnormalities within NSCLC as well as the development of tyrosine kinase inhibitors (TKIs) that target them (7).

Patients with untreated BM have been excluded from most clinical trials of systemic therapy for two reasons: (1) historically poor prognosis and (2) presumed poor blood-brain barrier (BBB) 
penetration by experimental drugs. Thus, the efficacy of these drugs in controlling NSCLC-related BM remains controversial.

In this review, the focus will be on targeted therapy and immunotherapy that show efficacy in BM rather than conventional treatment for multiple BM (such as surgical resection, WBRT, or SRS), or some combination of the three.

\section{ANAPLASTIC LYMPHOMA KINASE (ALK)-REARRANGED NSCLC}

The control and prevention of BM have emerged as an important therapeutic issue as systemic therapies with TKIs continue to improve the duration of disease control for patients with oncogene-driven NSCLCs (8). BM have been reported in about $24 \%$ of $A L K$-rearranged NSCLC patients at diagnosis, making intracranial activity an important feature of all $A L K$-targeted therapies (9).

\section{Crizotinib}

Crizotinib was the first $A L K$ and ROS1 (c-ros oncogene 1) inhibitor, approved for treatment of $A L K$-rearranged NSCLC. Crizotinib has shown evidence of potential clinical benefit in patients with a baseline of BM. PROFILE 1014, a phase 3 prospective study in $A L K$-positive NSCLC, demonstrated higher intracranial disease control rate (IDCR) with first-line crizotinib compared to chemotherapy in patients with treated BM. Although intracranial time to progression was improved, it was not significant (ITT population: $\mathrm{HR}, 0.60 ; 95 \% \mathrm{CI}, 0.34-1.05 ; P=0.069$; treated $\mathrm{BM}$ present: HR, 0.45; 95\% CI, 0.19-1.07; $P=0.063$; BM absent: HR, $0.69 ; 95 \% \mathrm{CI}, 0.33-1.45 ; P=0.323$ ) (10). In patients with $\mathrm{BM}$, the PFS was greatly improved with crizotinib versus chemotherapy (BM present: HR, 0.40; $P<0.001$; median, 9.0 versus 4.0 months, respectively) and in the intent-to-treat population (HR, 0.45; $P<0.001$; median, 10.9 versus 7.0 months, respectively). IDCR in patients with BM was significantly higher with crizotinib compared with chemotherapy (56 versus $25 \%$ at 24 weeks, respectively) (10) (Table $\mathbf{1}$ ).

Furthermore, a retrospective pooled analysis of single-arm phase 1 and 2 studies of crizotinib in advanced $A L K$-positive NSCLC, PROFILE 1007 (13) and 1005 (12), demonstrated a median overall survival (OS) of 29.6 months for 120 patients who were allowed to continue crizotinib beyond progressive disease (PD) because they continued to derive clinical benefit from it. Only $18 \%$ of previously untreated BM patients achieved an overall intracranial response rate (ICRR), with an IDCR of 56\% (95\% CI, 46-66\%) at 12 weeks (11) (Table 1).

Inevitably, the brain is the most common site of PD after resistance to crizotinib because of inadequate central nervous system (CNS) penetration of the drug or the biological change in the tumor (28). Hence, progression of preexisting or development of new intracranial lesions in up to $70 \%$ of patients while receiving therapy was a common manifestation of acquired resistance to crizotinib (29). Most systemic cytotoxic chemotherapies and some TKIs seem to cross the intact BBB inefficiently (30).

Limited intracranial response of crizotinib might be related to lower concentrations of the drug in cerebrospinal fluid compared with the plasma concentration ( 0.616 versus $237 \mathrm{ng} / \mathrm{mL}$, respectively, $5 \mathrm{~h}$ after administration of a $250 \mathrm{mg}$ dose) (31).

\section{Ceritinib}

Ceritinib is another $A L K$ inhibitor approved for $A L K$-rearranged NSCLCs that have progressed on crizotinib.

In vitro studies have found that ceritinib has a 20 -fold greater potency to inhibit $A L K$ than crizotinib and a 12 -fold greater potency than alectinib (32). Ceritinib was found to cross the intact $\mathrm{BBB}$ in rats with a brain-to-blood exposure ratio of approximately $15 \%$, although no human data exists (33).

In the phase 1 ASCEND-1 study, ceritinib demonstrated activity in $A L K$-rearranged locally advanced or metastatic cancer NSCLC patients, including both $A L K$-naïve and $A L K$-pretreated patients who had progressed following multiple lines of chemotherapy. Thirty one percent of the $A L K$ inhibitor-naive patients and $60 \%$ of $A L K$ inhibitor-pretreated patients had BM, respectively. There were 94 patients with retrospectively confirmed BM and at least one post-baseline imaging. IDCR was 79\% (15 of 19) in $A L K$ inhibitor-naïve patients and 65\% (49 of 75) in $A L K$ inhibitor-pretreated patients (14). Overall ICRR was 34.5\% (34) (Table 1).

In the ASCEND-2 phase 2 study, ceritinib showed a durable response in $A L K$-rearranged NSCLC patients who progressed on chemotherapy and crizotinib, including patients with BM. Moreover, 20 of the 100 patients with baseline BM had active target lesions at baseline. The investigator-assessed overall ICRR was $45 \%$ (95\% CI, 23.1-68.5\%), while the IDCR was $80 \%(n=20$, 95\% CI, 56.3-94.3) (15) (Table 1).

In the ASCEND-3 phase 2 study of ceritinib in ALK-inhibitornaïve NSCLC, $40.3 \%$ (50/124 patients) presented with BM at baseline. Fifty-four percent (27/50 patients) had received prior radiotherapy to BM. Updated data from ESMO 2016 showed an ICRR of $61.5 \%(8 / 13)$ in patients with measurable BM at baseline and an IDCR of $76.9 \%(10 / 13)$ (16) (Table 1).

\section{Alectinib}

Alectinib is another powerful $A L K$ inhibitor that has shown activity in crizotinib-resistant patients. A phase 2 study in $A L K$ positive NSCLC patients observed an objective response rate of $48 \%$ (35).

A hurdle in treating $\mathrm{BM}$ is achieving a higher rate of drug concentration in the brain because of the BBB. In animal models, alectinib has a high brain-to-plasma ratio (0.63-0.94) and activity in intracranial tumor implantation models (36). Alectinib penetrates into the CNS $(2.69 \mathrm{nmol} / \mathrm{L})$ where it is able to exceed the in vitro concentration for $A L K$ inhibition $(1.9 \mathrm{nmol} / \mathrm{L})(35,37)$. Alectinib human studies show a $50 \%$ CNS distribution, but of a 12 -fold lesser potency than ceritinib (33).

Unlike crizotinib and ceritinib, studies also suggest that alectinib is not a substrate of P-glycoprotein (P-gp), a key drug efflux pump typically expressed in the BBB (36), thus allowing for a higher rate of drug penetration through the $\mathrm{BBB}$.

Pooled data analysis of NP28761 and NP28673, two single-arm phase 2 trials, evaluated the CNS effect of alectinib in pretreated ALK-rearranged NSCLC patients (19). NP28761 was limited 
TABLE 1 | Intracranial effect of tyrosine kinase inhibitors ALK inhibitors and epidermal growth factor receptor (EGFR) inhibitors in trials in non-small cell lung cancer (NSCLC).

\begin{tabular}{|c|c|c|c|}
\hline Trial & Treatment & IDCR & ICRR \\
\hline \multicolumn{4}{|l|}{ ALK inhibitors } \\
\hline \multirow[t]{2}{*}{ PROFILE 1014 (10) } & Crizotinib & $56 \%$ at 24 weeks & Not described \\
\hline & PEM + CBDCA or CDDP & $25 \%$ at 24 weeks & Not described \\
\hline $\begin{array}{l}\text { Pooled analysis of Ref. (11) } \\
\text { PROFILE } 1005 \text { (12) } \\
\text { PROFILE } 1007 \text { (13) }\end{array}$ & Crizotinib & $56 \%$ at 12 weeks (previously untreated) & $18 \%$ (previously untreated) \\
\hline ASCEND-1 (14) & Ceritinib & $\begin{array}{l}65 \% \text { (pretreated) } \\
79 \% \text { (naïve) }\end{array}$ & $34.5 \%$ \\
\hline ASCEND-2 (15) & Ceritinib & $80 \%$ & $45 \%$ \\
\hline ASCEND-3 (16) & Ceritinib & $76.9 \%$ & $61.5 \%$ \\
\hline NCT01449461 (17) & Brigatinib & $\begin{array}{l}\text { 83\% (measurable) } \\
\text { 85\% (non-measurable) }\end{array}$ & $\begin{array}{l}50 \% \\
31 \%\end{array}$ \\
\hline NP28673 (18) & Alectinib & $\begin{array}{l}85.3 \% \\
84.5 \% \text { (pretreated) }\end{array}$ & $\begin{array}{l}58.8 \% \text { (measurable) } \\
46.4 \% \text { (non-measurable) }\end{array}$ \\
\hline NP28673 and NP28761 (19) & Alectinib & $\begin{array}{l}\text { 90.0\% (measurable BM) } \\
\text { 85.3\% (measurable and/or } \\
\text { non-measurable BM) }\end{array}$ & $\begin{array}{l}\text { 64.0\% (measurable BM) } \\
\text { 42.6\% (measurable and/or } \\
\text { non-measurable BM) } \\
\text { 35.8\% (prior RT) } \\
58.5 \% \text { (non-prior RT) }\end{array}$ \\
\hline J-ALEX (20) & Alectinib & $92.9 \%$ & $85.4 \%$ \\
\hline $\operatorname{ALTA}(21)$ & Brigatinib & $\begin{array}{l}88 \%(90 \mathrm{mg}) \\
83 \%(180 \mathrm{mg})\end{array}$ & $\begin{array}{l}36 \%(90 \mathrm{mg}) \\
67 \%(180 \mathrm{mg})\end{array}$ \\
\hline NCT01970865 (22) & Lorlatinib & Not described & $\begin{array}{l}\text { 44\% (targetable and non-targetable) } \\
60 \% \text { (targetable) }\end{array}$ \\
\hline \multicolumn{4}{|l|}{ EGFR inhibitors } \\
\hline $\begin{array}{l}\text { Pooled analysis of published data } \\
\text { Fan et al. (23) }\end{array}$ & Erlotinib or gefitinib & $75.7 \%$ & $51.8 \%$ \\
\hline $\begin{array}{l}\text { Retrospective analysis } \\
\text { Grommes et al. (24) }\end{array}$ & Pulsatile high-dose weekly erlotinib & Not described & $67 \%$ \\
\hline LUX-Lung 3 and LUX-Lung 6 (25) & Afatinib & Not assessed & Not assessed \\
\hline BLOOM (26) & Osimertinib & Not described & $\begin{array}{l}\text { 76\% (33\% LM improvement and } \\
43 \% \text { LM SD) }\end{array}$ \\
\hline BLOOM (27) & AZD3759 & Not described & $52.4 \%$ (measurable) \\
\hline
\end{tabular}

IDCR, intracranial disease control rate; ICRR, intracranial response rate; PEM, pemetrexed; CBDCA, carboplatin; CDDP, cisplatin; BM, brain metastases; RT, radiotherapy; LM, leptomeningeal metastases; $S D$, stable disease.

to North America only (NCT01871805), while NP28673 was a global study (NCT01801111). One hundred thirty-six patients had baseline measurable BM (60\% of the overall study populations). For patients with baseline measurable BM, the ICRR was 64.0\% (95\% CI, 49.2-77.1\%) with 11 (22\%) complete responses (CR) in the brain, the IDCR was $90.0 \%$ (95\% CI, 78.2-96.7\%), and the duration of response (DOR) was 10.8 months (95\% CI, 7.6-14.1 months) (19) (Table 1). For patients with measurable and/or non-measurable baseline BM, the IDCR was $42.6 \%$ (95\% CI, 34.2-51.4\%), the IDCR was $85.3 \%$ (95\% CI, 78.2-90.8\%), and the median DOR was 11.1 months (95\% CI, 10.3 months to not evaluable) (19). For patients with prior radiotherapy $(n=95)$, the ICRR was $35.8 \%$ (95\% CI, 26.2-46.3\%) and 58.5\% (95\% CI, $42.1-73.7 \%)$ for patients without prior radiotherapy $(n=41)$ (Table 1).

Updated intracranial response data on the 61/138 patients with baseline BM the global phase 2 NP28673 study was presented at
ESMO 2016. In the measurable BM group $(n=34)$, the ICRR was $58.8 \%$ (95\% CI, 40.7-75.4), while IDCR was $85.3 \%$ (95\% CI, 68.9-95.1) and the median DOR was 11.1 months (Table 1). In the measurable and non-measurable group $(n=84)$, the ICRR was $46.4 \%$ (95\% CI, 35.5-57.7), while IDCR was $84.5 \%$ (95\% CI, 78-91.5) and median DOR was 11.2 months (18) (Table 1).

More recently, J-ALEX, a phase 3 study comparing alectinib and crizotinib in treatment naive patients in Japan, showed an ORR of $85.4 \%$ in the alectinib group versus $70.2 \%$ in the crizotinib group (20). In patients with BM, the HR for alectinib versus crizotinib was 0.08 (95\% CI, 0.01-0.61). The J-ALEX trial enrolled 14 patients with asymptomatic BM in the alectinib arm. Only one of the patients with BM treated with alectinib had progressed by the time of data cut-off (IDCR of 92.9\%) (20) (Table 1). Thus, reducing CNS progression in patients with $A L K$-positive NSCLC with alectinib could be achievable if alectinib is used in the first-line setting. 
The Global ALEX trial is currently ongoing, also comparing alectinib versus crizotinib in first-line $A L K$-positive NSCLC but on a global scale. If the J-ALEX results are confirmed with this trial, alectinib could likely replace crizotinib as the standard firstline therapy for $A L K$-positive NSCLC in the future, especially those with BM.

\section{Brigatinib, Lorlatinib, and Others}

Brigatinib is an $A L K$ inhibitor with preclinical activity against rearranged $A L K$ and clinically identified crizotinib-resistant mutants. NCT01449461, a phase 1/2 single-arm, open-label, multicenter study in patients with advanced malignancies is ongoing. In a post hoc independent radiological review of patients with baseline $\mathrm{BM}, 6 / 12$ patients with lesions $\geq 10 \mathrm{~mm}$ had a brain response ( $\geq 30 \%$ decrease in sum of longest diameters of target lesions) and $8 / 26$ patients with only non-measurable lesions had disappearance of all lesions. ICRR for brigatinib with measureable BM was $50 \%$ and the IDCR was $83 \%$ (17). In non-measurable $\mathrm{BM}$, the ICRR was $31 \%$, IDCR was $85 \%$, median intracranial PFS was 97 weeks, and median duration of intracranial response 82 weeks (Table 1). In ALTA, a phase 2 trial of brigatinib, ORR in arm A (90 mg qd) was $46 \%$ while ORR in arm B (90 mg qd for 7 days followed by $180 \mathrm{mg} \mathrm{qd)} \mathrm{was} 54 \%$. Seventy-one percent (arm A) and 67\% (arm B) had BM (21) (Table 1).

Since CNS progression is a common site of relapse in NSCLC $A L K / R O S 1$ mutation patients, lorlatinib was developed as a selective brain-penetrant $A L K / R O S 1$ TKI active against most known resistance mutations. The phase 1 portion of the ongoing phase 1/2 study NCT01970865 enrolled patients with ALK+ or ROS1+ NSCLC with or without BM and were treatment naïve or had disease progression after $\geq 1$ TKIs. Preliminary results revealed an objective ICRR of $44 \%$ in targetable and non-targetable lesions and $60 \%$ in targetable lesion, respectively (22) (Table 1).

Additional second-generation $A L K$ inhibitors shown to have efficacy in the brain include ASP3026, X396, and entrectinib (38).

\section{EPIDERMAL GROWTH FACTOR RECEPTOR (EGFR) TKIs}

\section{First-Generation TKls}

Approximately 33\% of patients with NSCLC harboring tumors with EGFR-TKI-sensitizing mutations develop BM during treatment (39). Evidence suggests that EGFR TKIs have some limited BBB penetration $(40,41)$. In a pooled analysis including 464 patients from 16 trials to study the efficacy of EGFR TKIs in NSCLC patients with activating EGFR mutations with BM showed that EGFR TKIs produce significant beneficial effects, with a pooled objective ICRR of $51.8 \%$, IDCR of $75.7 \%$, median PFS of 7.4 months, and OS of 11.9 months (23) (Table 1).

Although erlotinib is effective for EGFR mutant NSCLC, CNS penetration is limited at standard daily dosing. Concentrations in cerebrospinal fluid exceeding the half maximal inhibitory concentration for EGFR mutant lung cancer cells in patients with BM and leptomeningeal metastases (LM) that developed despite standard daily erlotinib or other EGFR TKIs were achieved with weekly intermittent "pulsatile" administration of high-dose (1,500 mg) erlotinib (24). ICRR was 67\% (Table 1). Median time to CNS progression was 2.7 months (range, 0.8-14.5 months), and median OS was 12 months (range, 2.5 months-not reached) (24).

\section{Second-Generation TKI}

In both LUX-Lung 3 and LUX-Lung 6 studies, there was a non-significant trend toward improved PFS with afatinib versus chemotherapy in patients with asymptomatic BM (LUX-Lung 3:11.1 versus 5.4 months, $\mathrm{HR}=0.54, P=0.1378$; LUX-Lung 6:8.2 versus 4.7 months, $\mathrm{HR}=0.47, P=0.1060$ ) (25). In combined analysis, PFS was significantly improved with afatinib versus with chemotherapy in patients with $\mathrm{BM}$ (8.2 versus 5.4 months; $\mathrm{HR}=0.50 ; P=0.0297)(25)$.

Afatinib significantly improved the ORR versus chemotherapy in patients with BM. For LUX-Lung 3, ORR for afatinib was 70.0\% (95\% CI, 45.7-88.1) versus chemotherapy 20.0\% (95\% CI, 4.3-48.1) in patients with BM. The LUX-Lung 3 DCR for afatinib was $95.0 \%$ (95\% CI, 75.1-99.9) versus chemotherapy $80.0 \%$ (95\% CI, 51.9-95.7) in patients with BM. In LUX-Lung 6, ORR for afatinib was $75.0 \%$ (95\% CI, 55.1-89.3) versus chemotherapy $27.8 \%$ (95\% CI, 9.7-53.5) in patients with BM. The LUX-Lung 6 DCR for afatinib was $89.3 \%$ (95\% CI, 71.8-97.7) versus chemotherapy $72.2 \%$ (95\% CI, 46.5-90.3). There was no significant difference in OS in patients with BM who were treated with afatinib or chemotherapy.

These findings perhaps demonstrate a clinical benefit of afatinib in EGFR mutation-positive patients with NSCLC and asymptomatic BM. However, the role of afatinib in active BM remains to be clarified since this was an exclusion criterion in this study. ICRRs were not assessed in this study (Table 1). Therefore, no direct conclusions can be made regarding afatinib's ability to cross the $\mathrm{BBB}$ in concentrations sufficient to elicit CNS responses.

Despite limited evidence of EGFR TKIs providing benefit in a few patients with EGFR mutation-positive NSCLC with BM, a clinical need for novel EGFR TKIs with improved efficacy against BM still exists.

\section{Osimertinib in Leptomeningeal Disease}

Leptomeningeal metastases are seen in 3-5\% of NSCLC (42) and in $9 \%$ of EGFR mutation-positive patients (43). Osimertinib is an irreversible EGFR TKI that targets activating mutations (EGFRm) and resistance mutations (T790M). Osimertinib induced sustained tumor regression in an EGFRm PC9 mouse BM model. PET imaging showed higher levels of osimetinib levels in NHP and mouse models, in contrast to rociletinib and gefitinib (39).

In previous trials, osimertinib demonstrated robust systemic activity in patients with EGFRm NSCLC and BM and has shown CNS penetration with sustained tumor regression in BM (44). In the phase 1 BLOOM study, two third-generation EGFR TKIsosimertinib and AZD3759-were studied in patients with EGFR mutation-positive advanced NSCLC (26). Neurological function improved from baseline in 24\% (5/21) patients. Radiological improvements in LM were seen in 33\% (7/21) patients, and $43 \%$ $(9 / 21)$ had stable disease (SD) (Table 1). Clearance of tumor 
cells from the CSF occurred in two patients at two consecutive visits. Time on treatment suggests durable clinical benefit, with 15 patients remaining on treatment, 7 of whom have been on treatment for $>9$ months.

\section{AZD3759 in BM}

AZD3759 is a reversible inhibitor of EGFR-activating mutations that was designed to achieve high exposure in the plasma and CNS. AZD3759 has high passive permeability $\left(29.5 \times 10^{-6} \mathrm{~cm} / \mathrm{s}\right)$ and is not a substrate of the efflux transporters Pgp or BCRP at the $\mathrm{BBB}$. In vivo, AZD3759 reached distribution equilibrium in rats, mice, and monkeys ( $K_{\text {puu,brain }}$ and $K_{\text {puu,CSF }}>0.5$ ), suggesting BBB penetration (45). AZD3759 induced significant tumor regression and dramatically improved animal survival in the BM model (45).

The AZD3759 cohort of the BLOOM trial evaluated the safety, tolerability, and early efficacy of AZD3759 in 29 patients with advanced EGFR mutation-positive NSCLC and metastases, including LM (27). Patients with non-LM BM were required to have at least one measurable intracranial or extracranial lesion. Patients with LM had a diagnosis confirmed by positive CSF cytology. All patients received at least one prior line of EGFR TKI therapy and chemotherapy. In addition, 34\% of patients underwent prior whole-brain radiotherapy.

AZD3759 demonstrated encouraging intracranial antitumor activity. Among 21 patients with measurable BM, 11 patients demonstrated tumor shrinkage in the target brain lesion at AZD3759 doses of $\geq 50 \mathrm{mg}$ BID (Table 1). In this group, there were three confirmed partial responses $(\mathrm{PR})$ and three unconfirmed PRs. Among 22 patients with measurable extracranial lesions, 8 experienced tumor shrinkage, with 1 unconfirmed partial response. At the time of data cutoff, 5 of 29 patients remained on treatment with AZD3759. The longest duration of treatment was 48 weeks.

\section{Beyond EGFR and ALK}

Apart from EGFR mutation and $A L K$ translocations other distinct molecular subtypes of NSCLC depend on oncogenic molecular aberrations (driver mutations) for their malignant phenotype. Limited but promising data exist for the treatment of BM on novel molecular targets such as ROS1, BRAF, KRAS, HER2, c-MET, RET, PIK3CA, FGFR1, and DDR2 (46).

\section{IMMUNOTHERAPY}

\section{Nivolumab}

Nivolumab, a human IgG4 anti-PD-1 monoclonal antibody is active in the second-line treatment of metastatic NSCLC after progression on a platinum-based chemotherapy. Experience in routine clinical practice may differ from that seen in a controlled clinical trial. In a randomized phase 3 trial (CheckMate 017), the effect of nivolumab was studied in patients with advanced squamous NSCLC and central CNS metastases in a real-world, expanded access program (EAP) in Italy (47). Three hundred seventy-one patients participated in the EAP at 96 centers in Italy. Thirty-seven of 371 (10\%) patients had asymptomatic and controlled CNS metastases. The DCR was $49 \%$ among patients with CNS metastases, with $\mathrm{CR}$ in 1 patient, $\mathrm{PR}$ in 6 patients, SD in 11 patients, and PD in 19 patients (Table 2), while the ORR in patients with CNS metastases was 7/37 (19\%) (Table 2). OS rate at 12 months was 35\% for patients with CNS metastases and $39 \%$ for all patients. The median OS was 5.8 months $(95 \% \mathrm{CI}$, 1.8-9.8) for patients with CNS metastases and 7.9 months $(95 \%$ CI, 6.2-9.6) for all patients. The PFS rate at 12 months was $31 \%$ for patients with CNS metastases and $27 \%$ for all patients. The median PFS was 4.9 months (95\% CI, 2.7-7.1) for patients with CNS metastases and 4.2 months ( $95 \%$ CI, 3.4-5.0) for all patients.

In the Goldman et al. abstract 9,038 analysis presented ASCO 2016, pooled data from nivolumab studies [CheckMate 063 (50), CheckMate 017 (47), and CheckMate 057 (51)] were assessed to determine efficacy and safety of nivolumab in patients with previously treated, asymptomatic CNS metastases at baseline and patients with untreated, asymptomatic CNS metastases at baseline. The best response to most recent prior therapy demonstrated in the nivolumab with CNS metastases arm was CR/ PR of $13 / 46$ (28\%), SD of $15 / 46$ (33\%), and PD of $18 / 46(39 \%)$, compared to the docetaxel with CNS metastases arm with CR/PR 8/42 (19\%), SD 13/42 (31\%), and PD 18/42 (43\%) (48). Among patients with pretreated CNS metastases, median OS was longer in the nivolumab group (8.4 months; $95 \% \mathrm{CI}, 4.99-11.6)$ compared to the docetaxel group (6.2 months; 95\% CI, 4.4-9.23). The frequency of and time to new CNS lesions were similar across treatment groups. Furthermore, 8/46 (17\%) patients developed new CNS lesions in the nivolumab with CNS metastases arm with a median (range) of 3 (1.9-10.4) months, while 9/42 (21\%) patients developed new CNS lesions in the docetaxel with CNS metastases arm with a median (range) of 2 (0.5-8.0).

Moreover, in CheckMate 012 Arm M, 2 of 12 patients (16.7\%) with untreated CNS metastases achieved intracranial responses, including one intracranial CR lasting $>10.5$ months (48) (Table 2). These results support further investigation of nivolumab monotherapy in patients with NSCLC and asymptomatic CNS metastases.

\section{Pembrolizumab}

Pembrolizumab, a fully human anti-PD-1 monoclonal antibody is approved in first- and second-line treatment of metastatic NSCLC. NCT02085070 is a phase 2 study of pembrolizumab in patients with metastatic melanoma and NSCLC with untreated or progressive BM. The effect of drugs on untreated BM remains unclear because most clinical trials exclude these patients. Early data demonstrated that there was an ICRR of 6/18 (33\%) in the NSCLC on pembrolizumab $10 \mathrm{mg} / \mathrm{kg}$ arm, similar to the systemic response rate (49) (Table 2). The median OS was 7.7 months to date.

TABLE 2 | Effect of immunotherapy on BM in non-small cell lung cancer trials.

\begin{tabular}{llll}
\hline Trial & Treatment & IDCR & ICRR (\%) \\
\hline CheckMate 017 (47) & Nivolumab & $49 \%$ & 19 \\
CheckMate 012 (48) & Nivolumab & Not described & 16.7 \\
NCT12085070 (49) & Pembrolizumab & Not described & 33 \\
\hline
\end{tabular}

$B M$, brain metastases; IDCR, intracranial disease control rate; ICRR, intracranial response rate. 
The available data for the use of anti-PD-1 agents in the treatment of BM do not yet include data on PD-L1 status. These data when available could suggest higher response rates based on the level of PD-L1 positivity.

\section{CONCLUSION}

Current standard of care for BM that require immediate local intervention (based on symptoms, location, size, or other concerning features) is craniotomy with resection or radiation therapy. There is still a role in integrating locally ablative therapy (LAT) in combination with targeted therapy and immunotherapy in patients with oligometastatic BM that are limited or have low metastatic tumor burden (52).

Prior to the advent of second-generation therapies for BM developing while on crizotinib, the only alternatives were ablation of oligometastatic brain lesion with LAT and continuing crizotinib (28). Using WBRT with concurrent erlotinib (53)

\section{REFERENCES}

1. Torre LA, Bray F, Siegel RL, Ferlay J, Lortet-Tieulent J, Jemal A. Global cancer statistics, 2012. CA Cancer J Clin (2015) 65(2):87-108. doi:10.3322/caac.21262

2. Schuette W. Treatment of brain metastases from lung cancer: chemotherapy. Lung Cancer (2004) 45(Suppl 2):S253-7. doi:10.1016/j.lungcan.2004.07.967

3. Barnholtz-Sloan JS, Sloan AE, Davis FG, Vigneau FD, Lai P, Sawaya RE. Incidence proportions of brain metastases in patients diagnosed (1973 to 2001) in the Metropolitan Detroit Cancer Surveillance System. J Clin Oncol (2004) 22(14):2865-72. doi:10.1200/JCO.2004.12.149

4. Khan AJ, Dicker AP. On the merits and limitations of whole-brain radiation therapy. J Clin Oncol (2013) 31(1):11-3. doi:10.1200/JCO.2012.46.0410

5. Khuntia D, Brown P, Li J, Mehta MP. Whole-brain radiotherapy in the management of brain metastasis. J Clin Oncol (2006) 24(8):1295-304. doi:10.1200/ JCO.2005.04.6185

6. Halasz LM, Uno H, Hughes M, D’Amico T, Dexter EU, Edge SB, et al. Comparative effectiveness of stereotactic radiosurgery versus whole-brain radiation therapy for patients with brain metastases from breast or non-small cell lung cancer. Cancer (2016) 122(13):2091-100. doi:10.1002/cncr.30009

7. Garraway LA, Verweij J, Ballman KV. Precision oncology: an overview. J Clin Oncol (2013) 31(15):1803-5. doi:10.1200/JCO.2013.49.4799

8. Heon S, Yeap BY, Lindeman NI, Joshi VA, Butaney M, Britt GJ, et al. The impact of initial gefitinib or erlotinib versus chemotherapy on central nervous system progression in advanced non-small cell lung cancer with EGFR mutations. Clin Cancer Res (2012) 18(16):4406-14. doi:10.1158/1078-0432.CCR-12-0357

9. Rangachari D, Yamaguchi N, VanderLaan PA, Folch E, Mahadevan A, Floyd SR, et al. Brain metastases in patients with EGFR-mutated or ALK-rearranged non-small-cell lung cancers. Lung Cancer (2015) 88(1):108-11. doi:10.1016/j. lungcan.2015.01.020

10. Solomon BJ, Cappuzzo F, Felip E, Blackhall FH, Costa DB, Kim D-W, et al. Intracranial efficacy of crizotinib versus chemotherapy in patients with advanced ALK-positive non-small-cell lung cancer: results from PROFILE 1014. J Clin Oncol (2016) 34(24):2858-65. doi:10.1200/JCO.2015.63.5888

11. Ou S-H, Jänne P, Bartlett C, Tang Y, Kim D-W, Otterson GA, et al. Clinical benefit of continuing ALK inhibition with crizotinib beyond initial disease progression in patients with advanced ALK-positive NSCLC. Ann Oncol (2014) 25(2):415-22. doi:10.1093/annonc/mdu258

12. Riely G. Phase 2 data for crizotinib (PF-02341066) in ALK-positive advanced non-small cell lung cancer (NSCLC): PROFILE 1005. 14th World Conference on Lung Cancer. Amsterdam, The Netherlands: International Association for the Study on Lung Cancer (2011). p. 3-7.

13. Shaw A, Kim D, Nakagawa K, Seto T, Crinò L, Ahn M. Phase III study of crizotinib versus pemetrexed or docetaxel chemotherapy in patients with advanced ALK-positive non-small cell lung cancer (NSCLC) (PROFILE was also a viable option rather than changing to traditional chemotherapy.

However, recent data showing dramatic and prolonged responses in BM patients treated with EGFR and $A L K$ TKIs have suggested that delaying LAT and WBRT may be a valid treatment option for patients with asymptomatic BM from NSCLC, especially for those with $E G F R$-activating mutations or harboring $A L K$ rearrangement.

The challenge will be to determine the optimal sequence of agents and modalities (WBRT and SRS). Perhaps serial genotyping, the degree of BM symptoms, and the toxicity profiles will serve to individualize treatments and determine the role of these targeted therapies in the therapeutic armamentarium of BM.

\section{AUTHOR CONTRIBUTIONS}

The author confirms being the sole contributor of this work and approved it for publication.

1007). Presented at the European Society for Medical Oncolocy. Vienna, Austria (2012). ESMO LBA1-PR.

14. Kim DW, Mehra R, Tan DS, Felip E, Chow LQ, Camidge DR, et al. Activity and safety of ceritinib in patients with ALK-rearranged non-small-cell lung cancer (ASCEND-1): updated results from the multicentre, open-label, phase 1 trial. Lancet Oncol (2016) 17(4):452-63. doi:10.1016/S1470-2045(15) 00614-2

15. Crino L, Ahn MJ, De Marinis F, Groen HJ, Wakelee H, Hida T, et al. Multicenter phase II study of whole-body and intracranial activity with ceritinib in patients with ALK-rearranged non-small-cell lung cancer previously treated with chemotherapy and crizotinib: results from ASCEND-2. J Clin Oncol (2016) 34(24):2866-73. doi:10.1200/JCO.2015.65.5936

16. Felip E, Orlov S, Park K, Yu C-J, Tsai C-M, Nishio M, et al., editors. ASCEND-3: a single-arm, open-label, multicenter phase II study of ceritinib in ALKi-naive adult patients (pts) with ALK-rearranged (ALK+) non-small cell lung cancer (NSCLC). ASCO Annual Meeting Proceedings. Chicago, IL (2015).

17. Kerstein D, Gettinger S, Gold K, Langer C, Shaw A, Bazhenova L, et al. LBA4evaluation of anaplastic lymphoma kinase (ALK) inhibitor brigatinib [AP26113] in patients (PTS) with ALK+ non-small cell lung cancer (NSCLC) and brain metastases. Ann Oncol (2015) 26(Suppl 1):i60-1. doi:10.1093/ annonc/mdv128.06

18. Barlesi F, Dingermans AM, Yang JCH, Ou S-HI, Ahn JS, De Petris L, et al., editors. Updated efficacy and safety from the global phase II NP28673 study of alectinib in patients with previously treated ALK + non-small-cell lung cancer (NSCLC). Presented at the European Society for Medical Oncology. Copenhagen, Denmark (2016). ESMO Poster \#1263P.

19. Gadgeel SM, Shaw AT, Govindan R, Gandhi L, Socinski MA, Camidge DR, et al. Pooled analysis of CNS response to alectinib in two studies of pretreated patients with ALK-positive non-small-cell lung cancer. J Clin Oncol (2016) 34(34):4079-85. doi:10.1200/JCO.2016.68.4639

20. Nokihara H, Hida T, Kondo M, Kim YH, Azuma K, Seto T, et al., editors. Alectinib (ALC) versus crizotinib (CRZ) in ALK-inhibitor naive ALK-positive non-small cell lung cancer (ALK+ NSCLC): primary results from the J-ALEX study. ASCO Annual Meeting Proceedings. Chicago, IL (2016).

21. Kim D-W, Tiseo M, Ahn M-J, Reckamp KL, Holmskov Hansen K, Kim $\mathrm{S}-\mathrm{W}$, et al., editors. Brigatinib (BRG) in patients (pts) with crizotinib (CRZ)refractory ALK+ non-small cell lung cancer (NSCLC): first report of efficacy and safety from a pivotal randomized phase (ph) 2 trial (ALTA). ASCO Annual Meeting Proceedings Chicago, IL (2016).

22. Solomon B, Bauer T, Felip E, Besse B, James L, Clancy J. Safety and efficacy of lorlatinib (PF-06463922) from the dose-escalation component of a study in patients with advanced ALK+ or ROS1+ non-small cell lung cancer (NSCLC). Abstract 9009 Presented at ASCO Annual Meeting Proceedings in Chicago (2016) 
23. Fan $\mathrm{Y}, \mathrm{Xu} \mathrm{X}, \mathrm{Xie} \mathrm{C}$. EGFR-TKI therapy for patients with brain metastases from non-small-cell lung cancer: a pooled analysis of published data. Onco Targets Ther (2014) 7:2075-84. doi:10.2147/ott.s67586

24. Grommes C, Oxnard GR, Kris MG, Miller VA, Pao W, Holodny AI, et al. "Pulsatile" high-dose weekly erlotinib for CNS metastases from EGFR mutant non-small cell lung cancer. Neuro Oncol (2011) 13(12):1364-9. doi:10.1093/ neuonc/nor 121

25. Schuler M, Wu Y-L, Hirsh V, O'Byrne K, Yamamoto N, Mok T, et al. First-line afatinib versus chemotherapy in patients with non-small cell lung cancer and common epidermal growth factor receptor gene mutations and brain metastases. J Thorac Oncol (2016) 11(3):380-90. doi:10.1016/j.jtho.2015.11.014

26. Yang J, editor. Osimertinib activity in patients (pts) with leptomeningeal (LM) disease from non-small cell lung cancer (NSCLC): updated results from BLOOM, a Phase I study. Abstract 9002 [oral presentation]. Annual Meeting of the American Society of Clinical Oncology. Chicago, IL (2016).

27. Ahn M, Kim D, Kim T, Lin C, Ratnayake J, Carlie D, et al., editors. Phase I study of AZD3759, a CNS penetrable EGFR inhibitor, for the treatment of non-small-cell lung cancer (NSCLC) with brain metastasis (BM) and leptomeningeal metastasis (LM). Proceeding of the Annual Meeting of the American Society of Clinical Oncology, McCormick Place. Chicago, IL (2016).

28. Weickhardt AJ, Scheier B, Burke JM, Gan G, Lu X, Bunn PA, et al. Local ablative therapy of oligoprogressive disease prolongs disease control by tyrosine kinase inhibitors in oncogene-addicted non-small-cell lung cancer. J Thorac Oncol (2012) 7(12):1807-14. doi:10.1097/JTO.0b013e3182745948

29. Costa DB, Shaw AT, Ou S-HI, Solomon BJ, Riely GJ, Ahn M-J, et al. Clinical experience with crizotinib in patients with advanced ALK-rearranged nonsmall-cell lung cancer and brain metastases. J Clin Oncol (2015) 33(17):1881-8. doi:10.1200/JCO.2014.59.0539

30. Clarke JL, Pao W, Wu N, Miller VA, Lassman AB. High dose weekly erlotinib achieves therapeutic concentrations in CSF and is effective in leptomeningeal metastases from epidermal growth factor receptor mutant lung cancer. J Neurooncol (2010) 99(2):283-6. doi:10.1007/s11060-010-0128-6

31. Costa DB, Kobayashi S, Pandya SS, Yeo WL, Shen Z, Tan W, et al. CSF concentration of the anaplastic lymphoma kinase inhibitor crizotinib. J Clin Oncol (2011) 29(15):e443-5. doi:10.1200/JCO.2010.34.1313

32. Friboulet L, Li N, Katayama R, Lee CC, Gainor JF, Crystal AS, et al. The ALK inhibitor ceritinib overcomes crizotinib resistance in non-small cell lung cancer. Cancer Discov (2014) 4(6):662-73. doi:10.1158/2159-8290.CD-13-0846

33. Zykadia Core Data Sheet. version 1.2 ed. (2014). 15 p.

34. Shaw AT, Mehra R, Tan DS, Felip E, Chow L, Camidge DR, et al. 1293Pevaluation of ceritinib-treated patients (PTS) with anaplastic lymphoma kinase rearranged $(\mathrm{ALK}+)$ non-small cell lung cancer (NSCLC) and brain metastases in the ASCEND-1 study. Ann Oncol (2014) 25(Suppl 4):iv455-6. doi:10.1093/annonc/mdu349.72

35. Shaw AT, Gandhi L, Gadgeel S, Riely GJ, Cetnar J, West H, et al. Alectinib in ALK-positive, crizotinib-resistant, non-small-cell lung cancer: a single-group, multicentre, phase 2 trial. Lancet Oncol (2016) 17(2):234-42. doi:10.1016/ S1470-2045(15)00488-X

36. Kodama T, Hasegawa M, Takanashi K, Sakurai Y, Kondoh O, Sakamoto H. Antitumor activity of the selective ALK inhibitor alectinib in models of intracranial metastases. Cancer Chemother Pharmacol (2014) 74(5):1023-8. doi:10.1007/s00280-014-2578-6

37. Gadgeel SM, Gandhi L, Riely GJ, Chiappori AA, West HL, Azada MC, et al. Safety and activity of alectinib against systemic disease and brain metastases in patients with crizotinib-resistant ALK-rearranged non-small-cell lung cancer (AF-002JG): results from the dose-finding portion of a phase $1 / 2$ study. Lancet Oncol (2014) 15(10):1119-28. doi:10.1016/S1470-2045(14)70362-6

38. Zhang I, Zaorsky NG, Palmer JD, Mehra R, Lu B. Targeting brain metastases in ALK-rearranged non-small-cell lung cancer. Lancet Oncol (2015) 16(13):e510-21. doi:10.1016/S1470-2045(15)00013-3

39. Ballard P, Yang P, Cross D, Yates J, Finlay MR, Grist M, et al. Preclinical activity of AZD9291 in EGFR-mutant NSCLC brain metastases. Presented at the World Congress on Lung Cancer. Denver, CO, USA (2015).
40. Broniscer A, Panetta JC, O'Shaughnessy M, Fraga C, Bai F, Krasin MJ, et al. Plasma and cerebrospinal fluid pharmacokinetics of erlotinib and its active metabolite OSI-420. Clin Cancer Res (2007) 13(5):1511-5. doi:10.1158/10780432.CCR-06-2372

41. Zhao J, Chen M, Zhong W, Zhang L, Li L, Xiao Y, et al. Cerebrospinal fluid concentrations of gefitinib in patients with lung adenocarcinoma. Clin Lung Cancer (2013) 14(2):188-93. doi:10.1016/j.cllc.2012.06.004

42. Liao B-C, Lee J-H, Lin C-C, Chen Y-F, Chang C-H, Ho C-C, et al. Epidermal growth factor receptor tyrosine kinase inhibitors for non-small-cell lung cancer patients with leptomeningeal carcinomatosis. J Thorac Oncol (2015) 10(12):1754-61. doi:10.1097/JTO.0000000000000669

43. Kuiper J, Smit E. High-dose, pulsatile erlotinib in two NSCLC patients with leptomeningeal metastases-one with a remarkable thoracic response as well. Lung Cancer (2013) 80(1):102-5. doi:10.1016/j.lungcan.2012.12.024

44. Yang J, Ramalingam S, Jänne P, Cantarini M, Mitsudomi T. LBA2_PR: osimertinib (AZD9291) in pre-treated pts with T790M-positive advanced NSCLC: updated phase 1 (P1) and pooled phase 2 (P2) results. J Thorac Oncol (2016) 11(4):S152-3. doi:10.1016/S1556-0864(16)30325-2

45. Kim D-W, Yang JC-H, Chen K, Cheng Z, Yin L, Martin PD, et al., editors. AZD3759, an EGFR inhibitor with blood brain barrier (BBB) penetration for the treatment of non-small cell lung cancer (NSCLC) with brain metastasis (BM): preclinical evidence and clinical cases. ASCO Annual Meeting Proceedings. Chicago, IL (2015).

46. Rothschild SI. Targeted therapies in non-small cell lung cancer-beyond EGFR and ALK. Cancers (2015) 7(2):930-49. doi:10.3390/cancers7020816

47. Brahmer J, Reckamp KL, Baas P, Crinò L, Eberhardt WE, Poddubskaya E, et al. Nivolumab versus docetaxel in advanced squamous-cell non-small-cell lung cancer. N Engl J Med (2015) 373(2):123-35. doi:10.1056/NEJMoa1504627

48. Goldman JW, Crino L, Vokes EE, Holgado E, Reckamp KL, Pluzanski A, et al., editors. Nivolumab (nivo) in patients (pts) with advanced (adv) NSCLC and central nervous system (CNS) metastases (mets). ASCO Annual Meeting Proceedings. Chicago, IL (2016).

49. Goldberg SB, Gettinger SN, Mahajan A, Chiang AC, Herbst RS, Sznol M, et al. Pembrolizumab for patients with melanoma or non-small-cell lung cancer and untreated brain metastases: early analysis of a non-randomised, open-label, phase 2 trial. Lancet Oncol (2016) 17(7):976-83. doi:10.1016/ S1470-2045(16)30053-5

50. Rizvi NA, Mazières J, Planchard D, Stinchcombe TE, Dy GK, Antonia SJ, et al. Activity and safety of nivolumab, an anti-PD-1 immune checkpoint inhibitor, for patients with advanced, refractory squamous non-small-cell lung cancer (CheckMate 063): a phase 2, single-arm trial. Lancet Oncol (2015) 16(3):257-65. doi:10.1016/S1470-2045(15)70054-9

51. Borghaei H, Paz-Ares L, Horn L, Spigel DR, Steins M, Ready NE, et al. Nivolumab versus docetaxel in advanced nonsquamous non-small-cell lung cancer. N Engl J Med (2015) 373(17):1627-39. doi:10.1056/NEJMoa1507643

52. Bansal P, Rusthoven C, Boumber Y, Gan GN. The role of local ablative therapy in oligometastatic non-small-cell lung cancer: hype or hope. Future Oncol (2016) 12(23):2713-27. doi:10.2217/fon-2016-0219

53. Lind JS, Lagerwaard FJ, Smit EF, Senan S. Phase I study of concurrent whole brain radiotherapy and erlotinib for multiple brain metastases from non-small-cell lung cancer. Int J Radiat Oncol Biol Phys (2009) 74(5):1391-6. doi:10.1016/j.ijrobp.2008.10.026

Conflict of Interest Statement: The author declares that the research was conducted in the absence of any commercial or financial relationships that could be construed as a potential conflict of interest.

Copyright () 2017 Wong. This is an open-access article distributed under the terms of the Creative Commons Attribution License (CC BY). The use, distribution or reproduction in other forums is permitted, provided the original author(s) or licensor are credited and that the original publication in this journal is cited, in accordance with accepted academic practice. No use, distribution or reproduction is permitted which does not comply with these terms. 